DOI 10.37882/2500-3682.2020.12.35

\title{
СООТНОШЕНИЕ РАЗНЫХ ВИДОВ И СТОРОН ПАМЯТИ МЛАДШИХ ШКОЛЬНИКОВ С ИНТЕЛЛЕКТУАЛЬНОЙ НЕДОСТАТОЧНОСТЬЮ
}

\section{RELATIONSHIP OF DIFFERENT TYPES AND SIDES OF MEMORY OF THE MENTALLY RETARDED YOUNGER SCHOOL CHILDREN \\ E. Ushakova}

Summary: This article is devoted to the problem of inclusive education at the present stage of the development of society. Intellectual disability, as a result of memory impairment of students of primary school age, is considered in detail. A study of the volume of short-term auditory and visual memory was carried out. The features of recognition of mentally retarded children of primary school age were investigated, the volume of short-term auditory and visual memory was determined, the relationship of recognition with the volume of short-term auditory and the volume of short-term visual memory of mentally retarded primary schoolchildren was revealed and analyzed. The research results are presented.

Keywords: inclusion, education, law, student, developmental disorders, memory, forms and types, results.

\author{
Ушакова Елена Леонидовна \\ К.n.н., доцент, ФГБОУ ВО «Липецкий государственный \\ педагогический университет \\ имени П.П. Семенова-Тян-Шанского», Липецк \\ ushackowa.e@yandex.ru
}

Аннотация: Данная статья посвящена проблеме инклюзивного образования на современном этапе развития общества. Подробно рассмотрены интеллектуальная недостаточность, как следствие нарушения памяти обучающихся младшего школьного возраста. Проведено исследование объёма кратковременной слуховой и зрительной памяти. Исследованы особенности узнавания умственно отсталых детей младшего школьного возраста, определен объем кратковременной слуховой и зрительной памяти, выявлена и проанализирована взаимосвязь узнавания с объемом кратковременной слуховой и объемом кратковременной зрительной памяти умственно отсталых младших школьников. Представлены результаты исследования.

Ключевые слова: инклюзия, образование, закон, обучающийся, нарушения развития, память, формы и виды, результаты.

Бахуринская А.В. в своем научном труде писала: «Инклюзия является одной из последних стратегий специального образования. Это образование находится в России на начальной стадии развития и получает государственную нормативную поддержку в виде Конституции РФ, Федерального закона «Об образовании», Закона «О социальной защите инвалидов в Российской Федерации», а также большого количества международных конвенций» [3].

«Начало учебной деятельности - тяжелое испытание для многих детей, поступающих в первый класс, особенно для детей с ограниченными интеллектуальными возможностями. Им необходимо достаточное количество времени для того, чтобы привыкнуть к новым требованиям, новому коллективу и распорядку дня. В основном, обучающиеся в УО имеют мотивацию ходить в школу, но для многих из них распорядок дня, кажется, строго регламентирован.» [4].

«По сведениям, предоставленным Росстатом, общее количество детей-инвалидов в России постоянно возрастает. Так, если в 2016 году это было 617 тыс. человек, то в 2017 году - 636 тыс. детей, в 2018 году - 651 тыс. детей, а по данным на 1 января 2019 года возросло до 670 тыс. детей», - отмечается в общедоступном сообщении.

В своем научном труде, Бакланов О.С. пишет: «Характерной чертой дефекта умственной отсталости является 
недоразвитие не только познания, но и других аспектов умственной деятельности, то есть эмоционально-волевая сфера, речь, моторика и всей личности ребенка. У большинства детей с умственной отсталостью степень их недоразвития совпадает со степенью интеллектуального дефекта. Из чего следует, что дефект можно охарактеризовать как полнотой и относительная равномерность недоразвитости различных сторон психики ребенка. Тотальность, т.е. полнота, проявляется в том, что, так как все нервно-психические и даже соматические функции недоразвиты из-за врожденных пороков развития ряда внутренних органов (порок сердца, нарушение структуры желудочно-кишечного тракта и других систем), недоразвитие в росте костной, мышечной систем, чувствительности, моторики, простых эмоций до недоразвитию высших психических функций (речи, мышления) и личности в целом. Иерархия нервно-психического недоразвития заключается в недостатке гнозиса, практиса, речи, эмоций, памяти, и в большинстве случае, проявляется в меньшей степени, чем недоразвитие мышления, то есть в недоразвитии большинства психических функций страдает их основное ядро: память, внимание, восприятие и моторика»[2].

У детей со схожим дефектом заметны проблемы с когнитивными процессами, что является серьезной проблемой. К таким процессам, например, причисляется память. Память является по праву одним из самых важных когнитивных процессов человека, потому что это процесс восприятия, усвоения и последующего воспроизведения необходимой важной информации. Существует большое количество факторов, влияющих на умственную отсталость людей, необходимо найти силы и средства, чтобы предотвратить их влияние на психическое и физическое развитие. Исследование памяти обучающихся с ограниченными интеллектуальными возможностями - одна из актуальных проблем психологии [8].

Цель исследования: исследование взаимосвязи узнавания с объемом кратковременной слуховой памяти и объема кратковременной зрительной памяти.

\section{Задачи исследования:}

1. Изучить особенности распознавания умственно отсталых детей младшего школьного возраста.

2. Определить объем кратковременной слуховой и объем кратковременной зрительной памяти умственно отсталых младших школьников.

3. Выявить и проанализировать взаимосвязь узнавания с объемом кратковременной слуховой и объемом кратковременной зрительной памяти умственно отсталых младших школьников.

Проблема индивидуальных различий в соотношении сторон памяти учащихся начальной школы с задержкой умственного развития определена необходимостью создания оптимальных условий для их развития. В научных трудах Власовой Т.А., Выготского Л.С., Забрамной С.Д., Лурия А.Р. и других исследуются особенности памяти детей - олигофренов.

А.Р. Лурия писал: «Поэтому под памятью мы понимаем запечатление (запись), сохранение и воспроизведение следов прошлого опыта, что дает человеку возможность накапливать информацию и иметь дело со следами прошлого опыта, после исчезновения вызвавших их явлений»[9].

В статьях Г.М. Дульнева, Т.А. Власовой представлены результаты сравнительного исследования у детей с задержкой умственного развития «произвольной и непроизвольной памяти, а также запоминания и воспроизведения различных видов деятельности (труд и досуг).

В исследованиях С.Я. Рубинштейна, Е.М. Маслюковой, А.Д. Виноградовой уделяются особое внимание результатам исследования прочности и удержания памяти, а также особенностям запоминания [6; 10;15] .

Сохранение определенного материала в памяти обучающихся с задержкой умственного развития обладает своими особенностями. Нарушение процесса сохранения памяти у олигофренов выражается в быстром исчезновении сформированных связей и ассоциаций. Причины тому - функциональные нарушения процессов с высшей нервной деятельностью (ослабление замыкательной функции, патологическая инертность нервных процессов, возбуждение и торможение и др.). Известно, что функциональные нарушения тесно связаны с первичным дефектом - органическим поражением головного мозга. Но на специфику процесса сохранения большое влияние оказывают вторичные нарушения - недоразвитие личности умственно отсталых людей. По этой причине часто сохраняется не смысловое целостное содержание запоминаемого материала, а отдельные его части, заметные по цвету, форме, звуку и т. д. [7].

«Воспроизведение основано на качественном запоминании и сохранении. У детей с умственной отсталостью этот процесс также имеет свои специфические особенности. При отложенном и мгновенном воспроизведении обнаруживаются дополнения и замены, часто воспроизводимый материал искажается. Более того, в случае отсроченного воспроизведения эти дефекты оказываются более выраженными. В воспроизведенном материале часто обнаруживается отождествление, нарушение последовательности и неполнота содержания. Наибольшие искажения возникают при воссоздании вербального материала»[5].

Формирование смысловых и ассоциативных связей у умственно отсталых людей сильно нарушено, что проявляется в следующем:

- искажение, отсутствие структурного оформления 
смысловых связей,;

- быстрое угасание или случайная замена ассоциативных связей;

- преобладание образной памяти над словесно логической.

Специальная коррекционная работа оказывает содействие в устранении недостатков памяти. Организация и проведение учебно-воспитательной работы с уклоном на развитие осмысленного запоминания - один из наиболее эффективных способов оптимизации запоминания, сохранения и воспроизведения. В специальной психологии присутствуют подтверждения того, что у детей с умственной отсталостью с помощью специальной коррекционной работы логическая память начинает заметно развиваться после десятилетнего возраста. Объясняется это возрастным созреванием, развитием интеллектуальной деятельности, формированием структур личности, ведущих к сознательному и целенаправленному запоминанию и усвоению материала, а также пониманием важности учебной и практической деятельности.

Активная деятельность памяти начинается с запоминания, то есть с закрепления тех образов и впечатлений, возникающих в сознании под влиянием предметов и явлений действительности в процессе ощущения и восприятия. С точки зрения физиологии запоминание - это процесс образования и фиксации следов возбуждения в мозгу.

Успех в учебной деятельности обучающегося во многом зависит от успешности запоминания учебного материала. Запоминание может быть непроизвольным, если оно выполняется без заранее определенной цели запоминания и когда выполняется естественно, без волевых усилий.

Следующий процесс - «сохранение» - это удержание в памяти того, что было изучено и выучено, то есть поддержание следов и связей в мозгу. Забывание - исчезновение, небольшая потеря памяти, т.е. процесс угасания, устранения, «стирания» следов, торможения связей»[19].

Воспроизведение - процесс появления в сознании представлений памяти, ранее воспринятых мыслей, осуществление заученных движений, в основе чего лежит оживление следов, возникновение в них возбуждения. Узнавание - появление чувства знакомости при повторном восприятии (благодаря наличию слабого, минимального следа, который остался в коре головного мозга после предыдущего восприятия).

Воспроизведение в отличие от узнавания характеризуется тем, что образы, закрепленные в памяти, актуализируются (оживляются) без опоры на вторичное восприятие тех или иных объектов. Физиологически это означает наличие различных следов - стойких, прочных (воспроизведение) или слабых, нестойких и не прочных (узнавание).

- Образная память - это запоминание, сохранение и воспроизведение образов, ранее воспринимавшихся предметов и явлений действительности. Различают подвиды образной памяти - зрительную, слуховую, осязательную, обонятельную и вкусовую.

- «Словесно - логическая память выражается в запоминании, сохранении и воспроизведении мыслей, понятий, словесных формулировок»[19].

- Двигательная (моторная) память проявляется в запоминании и воспроизведении движений и их систем. Она лежит в основе выработки и формирования двигательных навыков (ходьбы, письма, трудовых и спортивных навыков и т.д.).

- «Эмоциональная память - это память на пережитые чувства, имеет большое значение в формировании личности человека. Она позволяет ему регулировать поведение в зависимости от ранее пережитых чувств. Пережитое и сохраненное в памяти чувства выступают как побудительные силы либо к совершению того или иного действия, поступка либо к отзыву от действия, если с ним связаны отрицательные переживания в прошлом»[18].

- Произвольная и непроизвольная память - эти виды памяти различаются в зависимости от степени волевой регуляции, от цели и способов запоминания и воспроизведения. Если не ставят специальной цели запомнить и припомнить тот или иной материал и последний запоминается как бы сам собой, без припоминания специальных приемов, без волевых усилий, то это память произвольная. Если ставят специальную цель запомнить, применяют соответствующие мнемические приемы, производят волевые усилия, то это память произвольная.

Память умственно отсталых детей формируется по тем же законам, что и у нормально развивающихся, но различные дефекты анализаторного аппарата и центральной нервной системы неизбежно сказываются на мнестических процессах.

«Необходимо указать и на такую особенность памяти, как эпизодическая забывчивость. Она связана с переутомлением нервной системы из-за общей ее слабости. У детей с умственной отсталостью отмечаются и трудности в воспроизведении образов восприятия - представлений. Недифференцированность, фрагментарность, уподобление образов и иные нарушения представлений отрицательно влияют на развитие познавательной деятельности умственно отсталых детей»[20].

Анализ материалов выявил особенности, которыми характеризуется мнестическая деятельность умственно отсталых школьников. Одной из них является нарушение соотношения между произвольным и непроизволь- 
ным запоминанием.

У умственно отсталых школьников нет существенных различий между продуктивностью преднамеренного и непреднамеренного запоминания.

Для того чтобы обучение детей протекало успешней и носило творческий характер, необходимо достаточно развитое воображение. У умственно отсталых детей оно отличается фрагментарностью, неточностью и схематичностью, так как их жизненный опыт беден, а смысловые операции несовершенны[20].

Умственно отсталые дети усваивают все новое очень медленно, лишь после многих повторений, быстро забывают воспринятое и, главное, не умеют вовремя воспользоваться приобретенными знаниями и умениями на практике. Замедленность и непрочность процесса запоминания проявляется прежде всего в том, что программу четырех классов массовой школы умственно отсталые дети усваивают за семь восемь лет обучения.

Причины замедленного и плохого усвоения новых знаний и умений кроются прежде всего в свойствах нервных процессов умственно отсталых детей. Слабость замыкательной функции коры головного мозга обуславливает малый объем и замедленный темп формирования новых условных связей, а также непрочность их. Кроме того, ослабление активного внутреннего торможения, обуславливающее недостаточную концентрированность очагов возбуждения, приводит к тому, что воспроизведение учебного материала многими умственно отсталыми детьми отмечается крайней неточностью[1].

Анализ материалов выявил особенности, которыми характеризуется мнестическая деятельность умственно отсталых школьников. Одной из них является нарушение соотношения между произвольным и непроизвольным запоминанием.

У умственно отсталых школьников нет существенных различий между продуктивностью преднамеренного и непреднамеренного запоминания.

С целью изучения взаимосвязи узнавания с объемом кратковременной слуховой памяти и объемом кратковременной зрительной памяти было проведено экспериментальное исследование с умственно отсталыми младшими школьниками коррекционной школы г. Липецка (второй класс 10 человек) и младшими школьниками с нормальным психическим развитием массовой школы (второй класс 10 человек).

В исследовании приняли участие двадцать детей.

На предварительном этапе разрабатывались, уточнялись методы исследования.

На первом этапе работы выполнена теоретическая проработка проблемы особенности памяти умственно отсталых детей. Был проведен срез, выявляющий особенности узнавания, объема зрительной и объема слуховой кратковременной памяти умственно отсталых младших школьников.

На втором этапе проводился анализ работы предшествующего этапа, были обобщены, описаны и математически обработаны результаты эксперимента и сформи- рован вывод по всей работе.

В процессе работы были использованы методики Р.С. Немова «Узнай фигуры», «Запомни рисунки», «Запомни цифры».

«Память ребенка младшего школьного возраста, как и его внимание, должна оцениваться не в целом, а дифференцированно, по отдельным показателям, и по каждому из них необходимо делать о памяти ребенка независимое заключение. Что же касается общих выводов о состоянии мнемических процессов у ребенка, то они имеют условное значение и только в общем характеризуют то, в какой степени развитой является его память»[11].

Сравнивая в целом результаты выполнения заданий умственно отсталыми детьми и детьми с нормальным умственным развитием, необходимо обратить внимание на поведение детей в процессе выполнения заданий. Умственно отсталые дети инертны, у них отсутствует интерес к заданию, и поэтому эмоциональный контакт со взрослыми, возник не сразу, а в течение эксперимента. Эмоциональное общение педагога и ребенка возникло на основе совместных действий, которые сопровождались приветливой улыбкой и ласковым голосом. После этого умственно отсталые дети приступили к выполнению задания.

При выполнении методики «Узнай фигуры» среди умственно отсталых детей были наиболее активными Денис Л., Олеся Г., Алина К. Они проявили интерес к заданиям, были заинтересованы результатами своей деятельности, справились со всеми заданиями быстро и правильно. Татьяна П., Егор Д. испытывали трудности в выполнении заданий. Они не поняли устные инструкции, однако показ им помог понять цель заданий и выполнить его. Такие дети, как Антон С., Артем Б. проявили меньше интереса к выполнению задания. Они были безразличны к результатам своей деятельности, не проявляли усилий в работе, до конца с заданием так и не справились. В процессе выполнения этой методики всем умственно отсталым детям требуется помощь со стороны взрослого, похвала, одобрение - для стимулирования их деятельности. В основном все дети медлительны при выполнении заданий.

При выполнении этой же методики детьми с нормальным умственным развитием того же возраста были получены совсем другие результаты. С детьми сразу же был установлен эмоциональный контакт. Они быстро поняли словесную инструкцию и цель задания, задания заинтересовали их. Помощь со стороны экспериментатора не требовалась. Все задания выполнены правильно и быстро.

Методика «Запомни рисунки и вызвала наибольший интерес у умственно отсталых детей. Данная методика предназначена для определения объема кратковременной зрительной памяти. При выполнении данной методики наиболее активными были Олеся Г., Денис Л. Словесную инструкцию экспериментатора и цель задания 
поняли и показали следующие результаты. Они запомнили и воспроизвели наибольшее количество фигур (по шесть). Хуже с тем же самым заданием справился Антон С., который запомнил и воспроизвел всего лишь две фигуры. Данная методика для Егора Д. не вызвала никакого интереса, он не был заинтересован в быстром и правильном выполнении задания, постоянно отвлекался. Вначале эксперимента Артур правильно воспроизвел две фигуры, а спустя некоторое время начал бесцельно показывать все подряд фигуры, пока его не остановил экспериментатор. Остальные умственно отсталые дети запомнили и воспроизвели от трех до шести фигур.

Данная методика была проведена с детьми, не имеющих отклонения в умственном развитии результаты исследования были значительно лучше. Больше всего фигур запомнили и воспроизвели Ольга Н., Марина 3. и некоторые другие учащиеся. Им удалось запомнить восемь фигур. Остальные дети запомнили от шести до семи фигур.

Сравнивая результаты выполнения данной методики детьми, имеющими недостатки в умственном развитии с умственно нормальными детьми, нужно отметить, что умственно отсталые дети находятся на среднем уровне развития кратковременной слуховой памяти, а дети в норме на высоком уровне.

При выполнении методики «Запомни цифры и умственно отсталыми детьми и детьми с нормальным умственным развитием были получены следующие результаты: при выполнении данной методики умственно отсталые дети проявили интерес к выполнению задания, инструкцию и цель задания поняли. Были получены следующие результаты. Лучше всего справилась с заданием Татьяна П., она безошибочно воспроизвела семь цифр. Самые худшие результаты показали такие дети, как Егор Д., Артем Б., Антон С. - эти дети воспроизвели по три цифры. Такие ученики как Олеся Г., Денис Л. воспроизвели по пять цифр.

При проведении этой же методики с детьми с нормальным умственным развитием того же возраста были получены следующие результаты. Дети задания выполняли активнее, проявили интерес к результатам своей деятельности. Самые лучшие результаты показали Марина 3., Людмила С., Ольга К., которые запомнили и воспроизвели по семь цифр.

Результаты проведенного исследования свидетельствуют о снижении уровня памяти умственно отсталых младших школьников по сравнению с тем, что наблюдается у их сверстников, развивающихся нормально.

В отличие от своих сверстников, у умственно отсталых младших школьников формирование смысловых «ассоциативных связей протекает с большими нарушениями. Смысловые связи искажаются, заменяются привнесениями, оказываются структурно неоформленными. Ассоциативные связи быстро угасают, случайно заменяются. Образная память преобладает над словесно-логической»[5].

Без специального обучения они значительно хуже, чем нормально развивающиеся дети запоминают учебный материал. Плохое понимание воспринимаемого материала приводит к тому, что учащиеся вспомогательной школы лучше запоминают внешние признаки предметов и явлений в их чисто случайных сочетаниях. Они с трудом запоминают внутренние логические связи и отношения, так как просто не вычленяют их. Также плохо понимают и запоминают отвлеченные словесные объяснения. Именно поэтому так важно умело и одновременно сочетать при изучении нового материала предъявление наглядных пособий с отвлеченными словесными объяснениями.

Характерной особенностью всех умственно отсталых младших школьников является неумение целенаправленно заучивать и припоминать. Когда умственно отсталым детям читают вслух рассказ, они стремятся запомнить наизусть отдельные фразы, но не вникая в его содержание. Учитель должен подсказать детям наиболее целесообразные приемы заучивания и припоминания учебного материала, помочь им сформировать эти сложные навыки. Поэтому «при обучении этих детей требуется специальная коррекционная работа, способствующая устранению недостатков в памяти. Проведение учебновоспитательной работы с установкой на развитие осмысленного запоминания - один из самых эффективных путей оптимизации запоминания сохранения и воспроизведения. В специальной психологии имеется указание на то, что после десятилетнего возраста у умственно отсталых детей при специальной коррекционной работе особенно заметно начинает развиваться логическая память. Это объясняется возрастным созреванием, развитием мыслительной деятельности, формированием личностных структур, приводящим к осознанному и целенаправленному запоминанию и усвоению материала, пониманию важности учебной и практической деятельности»[5].

Таким образом, в ходе работы была достигнута поставленная цель - были исследованы взаимосвязи узнавания с объемом кратковременной слуховой памяти и объема кратковременной зрительной памяти. Подробно были рассмотрены особенности узнавания умственно отсталых детей младшего школьного возраста, определены объемы кратковременной слуховой и зрительной памяти. Хотелось бы отметить, что в игровой деятельности этих детей проявляется бедность запаса знаний и представлений об окружающем мире, слабо выражен интерес к игре, беспорядочность и не целенаправленность игры, отсутствие творческих замыслом. Умственно отсталые младшие школьники затрудняются 
назвать то, чем в данный момент заняты. Их действия не соотносятся с речью.

Деятельность этих детей нуждается в постоянном стимулировании и контроле за ее ходом. Нет выраженной эмоциональной реакции на успех и ее удачу. Нередко отмечается отказ от коллективной игры. Учителю - дефектологу необходимо учить детей играть.

В заключение следует отметить, что «...память характеризуется достаточно сложными процессами, которые включают в себя свои механизмы. Также существуют различные виды памяти и их достаточно много. Каждый вид уникален, имеет свои особенности, но самое главное, каждый из них значим и необходим для полного развития умственных способностей человека. Несмотря на многолетний опыт исследования, и изучения памяти многие вопросы остаются не решёнными, но сейчас психология располагает обширным материалом по этой проблеме, и этого вполне достаточно, чтобы понять, что такое память, как она развивалась, и узнать различные подходы к изучению процессов памяти»[13].

\section{ЛИТЕРАТУРА}

1. Алентьева Е.А. Особенности развития психических процессов у детей с проблемами в интеллектуальном развитии// проблемы педагогики. - 2017. №3(26). - C. 37-43 URL: https://www.elibrary.ru/item.asp?id=28789886

2. Бакланова 0.С. Особенности памяти при умственной отсталости. [Электронный ресурс]. - URL: https://nsportal.ru/nachalnaya-shkola/ psikhologiya/2019/06/13/osobennosti-pamyati-pri-umstvennoy-otstalosti

3. Бахуринская А.В. Инклюзивное образование // Студенческий форум: электрон. научн. журн. 2020. № 28(121). URL: https://nauchforum.ru/journal/ stud/121/76330 (дата обращения: 05.11.2020).

4. Бетанова С.С. Развитие коммуникативных навыков детей младшего школьного возраста, имеющих легкую степень умственной отсталости // Вестник Московского государственного областного университета (Электронный журнал). 2012. № 3. с. 97-107.

5. Виноградова Л.Д. Практикум по психологии умственно отсталого ребенка: учеб. Пособие для студентов [Электронный pecypc]. - URL: http://disus.ru/ knigi/3536-1-praktikum-psihologii-umstvenno-otstalogo-rebenka-sostavitel-kandidat-psihologicheskih-pauk-d-vinogradova-dopuscheno-mini.php

6. Власова Г.А. Отбор детей во вспомогательную школу. - М.: «Просвещение», 1983. - 176 с.

7. Григорьевская И.В. Особенности произвольной и непроизвольной памяти умственно отсталых детей // Психология и педагогика: методика и проблемы практического применения. - 2008. - №1. - С. 354-358 URL: https://www.elibrary.ru/item.asp?id=21134016

8. Долгова В.И., Капитанец Е.Г., Сметанина Д.А. Исследование видов памяти у младших школьников с интеллектуальными нарушениями // Научно-методический электронный журнал «Концепт». - 2015. - Т. 31. - С. 111-115. - URL: http://e-koncept.ru/2015/95529.htm.

9. Лурия А.Р. Лекции по общей психологии. [Электронный ресурс]. - URL:https://bookap.info/genpsy/luriya_lektsii_po_obshchey_psihologii/gl54.shtm

10. Методы исслендования детей при отборе во вспомогательные школы./Под ред. А.Р. Лурия, В.И. Лубовского. - М.: «Просвещение», 1964. - 120 с.

11. Немов Р.С. Психодиагностика: Учеб. для студ. высш. пед. учеб. заведений: В 3 кн. — 4-е изд. — М.: Гуманит. изд. центр ВЛАДОС, 2001. — Кн. 3: Психодиагностика. Введение в научное психологическое исследование с элементами математической статистики. — $640 \mathrm{c}$.

12. Обучение и воспитание умственно отсталых детей./Под.ред. Г.М. Дульневой, - Из-во «Академия пед-ких наук», 1960. - 152 с.

13. Парфёнова Е.А., Репринцева Ю.С. Теоретико-методологические основы исследования памяти // Студенческий форум: электрон. научн. журн. 2019. № 20(71). URL: https://nauchforum.ru/journal/stud/71/53106 (дата обращения: 05.11.2020).

14. Психолого-педагогическая диагностика умственного развития детей. /Под ред. С.Д. Забрамной, - М.: «Просвещение», 1985. - 190 с.

15. Рубинштейн С.Я. Психология умственно отсталого школьника. - М.: «Просвещение», 1986. - 192 с.

16. Стародубов В.И., Пузин С.Н., Амасьянц Р.А. Стратегия формирования и развития системы организации комплексной реабилитации детей-инвалидов в Российской Федерации: Монография. - М., 2006, - 300 с.

17. Тезисы докладов II международной конференции «Развитие инклюзивных школ». -M., 2011 г.

18. Фахрутдинова Р. А., Ахмадуллина Р.М. Развитие памяти одаренных школьников на младшем этапе обучения (на материале экспериментального исследования) // Филология и культура. - 2014. - №3(37). - C. 288-294 URL: https://www.elibrary.ru/item.asp?id=22939607

19. Физиологические основы памяти [Электронный ресурc]: - URL: https://vikidalka.ru/3-102336.html

20. Щербетова А.Ю. Особенности познавательной деятельности дошкольников с нарушением интеллекта// Проблемы педагогики. - 2018. - №7(39). C. 54-69 URL: https://www.elibrary.ru/item.asp?id=36654372

(c) Ушакова Елена Леонидовна (ushackowa.e@yandex.ru). 